www.jmscr.igmpublication.org

Impact Factor (SJIF): 6.379

Index Copernicus Value: 71.58

ISSN (e)-2347-176x ISSN (p) 2455-0450

crossref DOI: _https://dx.doi.org/10.18535/jmscr/v6i3.218

Journal Of Medical Science And Clinical Research

\title{
Adverse Reactions Associated with Single Donor Plateletpheresis Procedures in tertiary care centre at M.Y. Hospital, Indore
}

\author{
Authors \\ Dr Amrita Tripathi ${ }^{1}$, Dr Ashok Yadav ${ }^{2}$, Dr Priyanka Solanki ${ }^{3}$ \\ ${ }^{1,3}$ Senior Resident, Department of Pathology, MGM Medical College, Indore (M.P.) \\ ${ }^{2}$ Professor, Department of Pathology, MGM Medical College, Indore (M.P.) \\ Corresponding Author \\ Dr Priyanka Solanki
}

Senior Resident, Department of Pathology, MGM Medical College, Indore (M.P.) India

Email: pinka15sept@gmail.com, Contact no.-9131630312

\begin{abstract}
Background: Plateletpheresis is a procedure where the whole blood is processed from a donor and the platelets are separated and the remaining blood components are returned back to the donor. Adverse reactions of variable severity may occur during or after the procedure. Adverse reactions that occur in donors can be divided into local reactions and systemic reactions.

Methods: In this study 65 healthy voluntary donors were enrolled after taking the informed written consent and adverse donor reactions of plateletpheresis were noted.

Results: It was observed that out of 65 donors, only three donors had adverse reactions during plateletphersis. Citrate toxicity was seen in one donor (1.6\%), one donor (1.6\%) had bruising on the arm at venipuncture site and another one donor had vasovagal reactions (1.6\%) occur mainly in the form of sweating.

Conclusion: Plateletpheresis is one of the well tolerated procedure in which adverse reactions were managed conservatively and rarely need hospitalization.

Keywords: Adverse reactions, Plateletpheresis, Citrate toxicity, vasovagal reactions.
\end{abstract}

\section{Introduction}

Plateletpheresis is a procedure where the whole blood is processed from a donor and the platelets are separated and the remaining blood components are returned back to the donor. As nearly all red blood cells (RBC) and white blood cells (WBC) can be returned to the donor, it is common practice to repeat apheresis donations at close intervals. ${ }^{[1]}$ Increased demand for platelet transfusion implies the need to recruit greater numbers of donors and ensuring the safety of donors is a crucial factor in recruitment. ${ }^{[2-4]}$ Apheresis procedures are usually well tolerated. Adverse reactions of variable severity may occur during or after the procedure. AEs that occur in donors can be divided into local reactions and systemic reactions. ${ }^{[5,6]}$

Local reactions are usually haematomas due to extravasation from the veins, caused by incorrect placement of the needle during the venipuncture. 
Pain, hyperaemia and swelling may develop at the site of the extravasation. Local phlebitis and thrombophlebitis are very rare. ${ }^{[6,7]}$

Systemic reactions are mainly vasovagal reactions that can be triggered by the pain of the venipuncture, or by the anxiety and state of tension of undergoing the donation, etc. These are characterised by the pallor, sweating, dizziness, nausea, hypotension, bradycardia, and syncope. Citrate toxicity occurs because of the use of acidcitrate-dextrose (ACD) in apheresis. ${ }^{[7-9]}$

\section{Materials and Methods}

This retrospective, observational, non blinded study conducted in M.Y. Hospital, Indore included a total of 65 healthy voluntary donors after taking informed written consent. Donors were selected as per the set criteria for single donor platelet (SDP) preparation according to AABB guidelines:

(i) Weight $>50 \mathrm{~kg}$

(ii) Age - 18 to 60 years

(iii) At least three months from last donation/three days from last Plateletpheresis

(iv) Haemoglobin $>12.5 \mathrm{gm} / \mathrm{dl}$

(v) Platelet count $>150 \times 103 / \mu 1$ (vi) Absence of any illness

(vii) No consumption of non-steroidal antiinflammatory drugs for last seven days

(viii) Negative test for HIV, Hepatitis B, Hepatitis C, Syphilis and Malaria.

The adverse events during the process of plateletpheresis using MCS+ has been broadly divided into,

(i) Venipuncture related,

(ii) Syncope/faintness/sweating and N/V and,

(iii) Citrate reactions

\begin{tabular}{|l|l|}
\hline Adverse Reaction & \multicolumn{1}{|c|}{} \\
\hline Venipuncture related, & $\begin{array}{l}\text { pain at phlebotomy site, } \\
\text { Haematoma }\end{array}$ \\
\hline Vasovagal reaction & $\begin{array}{l}\text { Syncope/faintness/sweating and } \\
\text { N/V and Loss of consciousness } \\
\text { and seizures }\end{array}$ \\
\hline Citrate reactions & Circumoral paresthesia, Tetany \\
\hline
\end{tabular}

\section{Results}

Table 2: Adverse Reaction of Plateletpheresis Procedure on Donors.

\begin{tabular}{|l|c|}
\hline Adverse Reaction & No. of donors (\%) \\
\hline Venipuncture related, & $01(1.6 \%)$ \\
\hline Vasovagal reaction & $01(1.6 \%)$ \\
\hline Citrate reactions & $01(1.6 \%)$ \\
\hline Total & $03(4.6 \%)$ \\
\hline
\end{tabular}

Figure-1 Adverse Reaction of Plateletpheresis Procedure on Donors

\section{Adverse Reaction of Plateletpheresis Procedure on Donors}

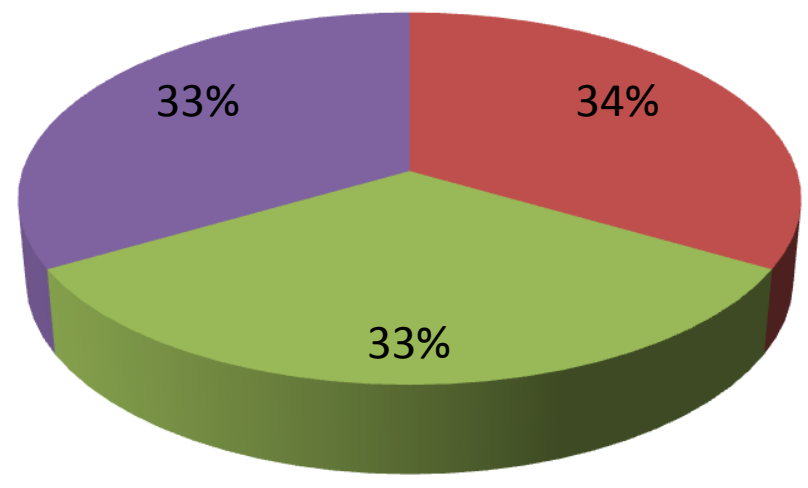

Venipuncture related,

Vasovagal reaction

Citrate reactions 
During donation it was observed that out of 65 donors, only three donors had adverse reactions during plateletpheresis. Citrate toxicity was seen in one donor which may be due to the reason that to get high platelet yield with respect to lower platelet count leads to more amount of whole blood has to be processed so more ACD run in the blood circulation which caused citrate toxicity as circumoral paresthesia,. Another donor had bruising on the arm at venipuncture site due tortuous vein, another donor had vasovagal reactions (syncope/faintness/sweating) occur mainly in the form of sweating. This can possibly be attributed to apprehension due to mechanical and psychological factors, possibly attributable to the noise generated by the machine, and due to the fact that over a period of time, the donor got more stressed. All of these were managed conservatively and none of the donor needed hospitalization.

\section{Discussion}

Table 3: Comparison of adverse effect of plateletpheresis donation with other studies

\begin{tabular}{|l|l|l|}
\hline $\begin{array}{l}\text { Sr } \\
\text { No. }\end{array}$ & \multicolumn{1}{|c|}{ Study } & No. of donors (\%) \\
\hline 1 & Dogra et al[10] (2016) & 80 out of $1740(4.59 \%)$ \\
\hline 2 & Joseph et al[11] (2013) & 90 out of 3367(2.67\%) \\
\hline 3 & Kajal et al[12] (2017) & 04out of 66(6.0\%) \\
\hline 4 & Garg et al[13] (2017) & 02out of 100(2.0\%) \\
\hline 5 & Present Study (2018) & 03 out of 65(4.6\%) \\
\hline
\end{tabular}

In the present study, the adverse reaction on donors during plateletpheresis was $4.6 \%$ which is similar to study done by Dogra et al, $(4.59 \%)^{[10]}$ While the studies conducted by Joseph et al, $(2.67 \%)^{[11]}$ and Garg et al, $(2.0 \%)^{[13]}$ Adverse reaction during plateletpheresis donation which is lower while Kajal et al, $(6 \%){ }^{[12]}$ had higher than present study.

\section{Conclusion}

Plateletapheresis is a safe procedure and adverse reactions are less acute than whole blood donation and rarely need hospitalization. The acute effects of donation are relatively mild and easily treated.
The adverse reactions during plateletpheresis can be reduced by scrupulous donor-vigilance and trained technical personnel. Additional research is needed to ascertain the risks of long-term apheresis donation.

\section{References}

1. Heuft HG, Moog R, Fi scher EG, Zingsem J. German and Austrian Plateletpheresis Study Group. Donor safety in triple plateletpheresis results from the German and Austrian Plateletpheresis Study Group multicenter trial. Transfusion 2013;53:211-20.

2. Hagberg IA, Akkok CA, Lyberg T, Kragh JK. Comparison of three types of cell in apheresis induced platelet activation separators 2000;40:182-92

3. Patel AP, Kaur A, Patel V, Patel N, Shah D, Kanvinde S. Comparative study of platelet pheresis using Baxter CS 3000 plus and Haemonetics MCS 3P. J Clin Apher 2004;19:137-41.

4. Wallace EL, Churchill WH, Surgenor DM, Cho GS, McGurk S. Collection and transfusion of blood and blood components in the United States 1994. Transfusion 1998; 38:625-36.

5. Mcleod BC, Price TH, Owen H, Ciavarella D, Sniecinski I, Randels MJ, et al. Frequency of immediate adverse effects associated with apheresis donation. Transfusion. 1998;38:938-43. [PubMed: 9767744]

6. Winters JL. Complications of donor apheresis. J Clin Apher. 2006;21:13241. [PubMed: 15880355]

7. Brecher ME, Leger RM. AABB technical manual. 15th ed. Bethesda: American Association of Blood Banks; 2005.

8. Simon TL, Dzik WH. Rossi's principles of transfusion medicine. 4th ed. Philadelphia: Lippincott Williams \& Wilkins; 2009. 
9. Crookes RL, Hillyer CD. Blood banking \& transfusion medicine. 2nd ed. Philadelphia: Churchill Livingstone; 2009.

10. Kanchan Dogra, Parag Fulzele, Diptiranjan Rout, Rahul Chaurasia, Poonam Coshic, Kabita Chatterjee Adverse Events During Apheresis Procedures: Audit at a Tertiary Hospital. Indian Journal of Hematology \& Blood Transfusion 2017;33 (1): 106-108

11. Joseph Philip, Ravi S. Sarkar, and Amardeep Pathak Adverse events associated with apheresis procedures: Incidence and relative frequency. Asian $\mathbf{J}$ Transfus Sci. 2013; 7(1): 37-41.

12. Kajal Khajuria, Vijay Sawhney, Raman Sharma, Sonia Gup Adverse donor reaction during and after plateletpheresis in a tertiary care centre Int J Res Med Sci. 2017;5(4):1221-1223

13. Garg P, Bassi R, Bharadwaj K, Bodal VK. Study of Adverse Donor Reaction of Plateletpheresis in a Tertiary Care Centre of North India. Ann. Int. Med. Den. Res. 2018; 4(2): PT46-PT47. 